\title{
Impacto no cotidiano das pessoas com a manifestação de hanseníase na região de
}

\author{
cabeça e pescoço \\ Impact of head and neck leprosy presentations on the daily lives of people with the disease \\ Impacto cotidiano en personas con manifestación de lepra en la región de cabeza y cuello
}

Recebido: 29/06/2021 | Revisado: 05/07/2021 | Aceito: 07/07/2021 | Publicado: 17/07/2021

Danielle de Oliveira Teodósio Assis

ORCID: https://orcid.org/0000-0001-5899-7171 Centro Universitário CESMAC, Brasil

E-mail: daniteodosio@hotmail.com

Clodis Maria Tavares

ORCID: https://orcid.org/0000-0001-6804-3064 Universidade Federal de Alagoas, Brasil E-mail: clodistavares@yahoo.com.br

Raabe Alves de Araújo Alcântara

ORCID: https://orcid.org/0000-0001-9665-6247 Centro Universitário CESMAC, Brasil E-mail: raabe_alves@hotmail.com

Lívia Jatobá Ramirez

ORCID: https://orcid.org/0000-0003-0780-0038 Centro Universitário CESMAC, Brasil

E-mail: livjatoba@gmail.com

Evanisa Helena Maio de Brum

ORCID: https://orcid.org/0000-0003-0128-591X Centro Universitário CESMAC, Brasil E-mail: evanisa.brum@gmail.com

Kevan Guilherme Nóbrega Barbosa ORCID: https://orcid.org/0000-0002-9410-7356 Centro Universitário CESMAC, Brasil E-mail: kevanguilherme@gmail.com

Mara Cristina Ribeiro

ORCID: https://orcid.org/0000-0001-6963-8158 Centro Universitário CESMAC, Brasil E-mail: maracrisribeiro@gmail.com

\begin{abstract}
Resumo
A hanseníase é uma doença infectocontagiosa, crônica, transmissível, de notificação compulsória e investigação obrigatória em todo o território nacional. O estudo tem como objetivo avaliar o impacto no cotidiano das pessoas atingidas com manifestações de hanseníase na região cabeça e pescoço. Trata-se de um estudo do tipo exploratório descritivo com abordagens qualitativa, realizado em uma Unidade de Referência em Saúde para tratamento de hanseníase, em Maceió. Foi aplicado um formulário semiestruturado referente aos impactos no cotidiano dos participantes atingidos pela hanseníase. Foram identificados 6 fatores que se destacaram e dizem respeito ao impacto da hanseníase no cotidiano desses pacientes. A partir dessa percepção, foram geradas 6 categorias temáticas, a saber: Trajetória percorrida até chegar ao diagnóstico de hanseníase; Vivência e sentimentos das pessoas atingidas pela Hanseníase; Mudanças ocorridas no convívio social, familiar e profissional; Impacto das manifestações na região de cabeça e pescoço no cotidiano das pessoas atingidas pela hanseníase; O estigma e o meio social; e, Superação das dificuldades decorrentes das manifestações na região de cabeça e pescoço. Por fim, a hanseníase causa um impacto significativo na vida e cotidiano das pessoas atingidas. O diagnóstico precoce, tratamento adequado e acompanhamento multidisciplinar contínuo e qualificado são de suma importância.
\end{abstract}

Palavras-chave: Hanseníase; Manifestação bucal; Estigma social; Doenças transmissíveis.

\begin{abstract}
Leprosy is a chronic infectious and transmissible disease, of compulsory notification and investigation in the entire national territory. The objective of this study was to evaluate the impact of head and neck clinical presentations on the daily life of people affected by leprosy. This is an exploratory, descriptive study, using a qualitative approach, carried out at a reference health unit for leprosy treatment, in Maceió. A semi-structured form was applied regarding the impacts on the daily lives of the participants affected by leprosy. Six factors were identified, as they stood out regarding the impact of leprosy on the daily lives of these patients. This perception resulted in six thematic categories, namely: the Path taken to reach the diagnosis of leprosy; Experience and feelings of people affected by leprosy;
\end{abstract}


Changes in social, family and professional life; Impact of the head and neck presentations of the disease on the daily lives of people affected by leprosy; social Stigma and environment; and, Overcoming the difficulties arising from the head and neck presentations of the disease. Thus, leprosy has a significant impact on the daily lives of people affected by the disease. Early diagnosis, proper treatment and continuous multiprofessional and qualified follow-up are extremely important.

Keywords: Leprosy; Oral manifestation; Social stigma; Communicable diseases.

\section{Resumen}

La lepra es una enfermedad infectocontagiosa, crónica, transmisible, de notificación compulsiva e investigación obligatoria en todo el territorio nacional. El estudio objetiva evaluar el impacto cotidiano en las personas alcanzadas por manifestaciones de lepra en región de cabeza y cuello. Estudio de tipo exploratorio, descriptivo, con abordaje cualitativo, realizado en Unidad de Referencia en Salud para tratamiento de lepra en Maceió. Fue aplicado formulario semiestructurado referente a los impactos cotidianos en los participantes afectados por lepra. Fueron identificados 6 factores que destacaron respecto del impacto de la lepra en el cotidiano de los pacientes. Partiendo de dicha percepción, fueron generadas 6 categorías temáticas, a saber: Trayecto recorrido hasta llegar al diagnóstico de lepra; Vivencia y sentimientos de personas alcanzadas por la lepra; Cambios ocurridos en la convivencia social, familiar y profesional; Impacto de las manifestaciones en región de cabeza y cuello en el cotidiano de personas afectadas por lepra; El estigma y el medio social; y Superación de dificultades derivadas de manifestaciones en región de cabeza y cuello. La lepra provoca impacto significativo en la vida y en el cotidiano de las personas afectadas. Diagnóstico precoz, tratamiento adecuado y seguimiento multidisciplinario, continuado y calificado resultan de suma importancia.

Palabras clave: Leprosy; Oral manifestation; Social stigma; Enfermedades transmisibles.

\section{Introdução}

A hanseníase é uma doença infectocontagiosa crônica, transmissível, de notificação compulsória e investigação obrigatória em todo o território nacional. Possui como agente etiológico o Mycobacterium leprae, bacilo que atinge principalmente a pele e os nervos periféricos, com capacidade de ocasionar lesões neurais, o que lhe confere um alto poder incapacitante, principal responsável pelo estigma e discriminação em relação às pessoas acometidas pela doença (Brasil, 2020).

Segundo as Diretrizes para o diagnóstico, tratamento e prevenção da hanseníase, da Organização Mundial da Saúde, publicado em 2019, em 2018 foram reportados 208.619 casos novos de hanseníase no mundo, resultando em uma taxa de detecção de 2,74 casos por 100.000 habitantes. No Brasil, no mesmo ano, foram notificados 28.660 casos com uma taxa de detecção de 13,70 casos/100.000 habitantes. Desta forma, o Brasil está entre os 22 países com as mais altas cargas de hanseníase do mundo, ocupando a $2^{\mathrm{a}}$ posição em relação à detecção de casos novos (Brasil, 2020).

A hanseníase ainda é um problema de saúde pública no Brasil, pela sua magnitude, gravidade e alto poder incapacitante associado ao estigma que desenvolve impactos físicos, psicológicos, sociais e econômicos no cotidiano da pessoa acometida por esta doença. Cotidianamente, as pessoas atingidas pela hanseníase reagem impactadas pela desesperança, tristeza, raiva, culpa, vergonha, sentem medo de enfrentar as pessoas, a sociedade e, muitas vezes, são julgadas pela falta de conhecimento e assombradas pelo estigma milenar e histórico que envolve esse agravo, visto que a hanseníase tem tratamento e cura (Brasil, 2019). Assim, este estudo teve por objetivo avaliar o impacto das manifestações na região de cabeça e pescoço no cotidiano das pessoas atingidas pela hanseníase.

O estudo tem como objetivo avaliar o impacto no cotidiano das pessoas atingidas com manifestações de hanseníase na região cabeça e pescoço.

\section{Metodologia}

Trata-se de um estudo do tipo exploratório descritivo com abordagens qualitativa, realizado em uma Unidade de Referência em Saúde para tratamento de hanseníase, em Maceió. Foi aplicado um formulário semiestruturado referente aos impactos no cotidiano dos participantes atingidos pela hanseníase.

Este estudo obteve autorização da Secretária de Saúde do Município de Maceió e foi aprovada pelo Comitê de Ética 
em Pesquisa (CEP) sob número de parecer no - 3. 942.098, autorizada em 30 de março de 2020, emenda no 4.33.8.205, de 14 de outubro de 2020, CAAE- 26966619.0.0000.0039.

$\mathrm{O}$ estudo contou com uma amostra de 41 participantes que no momento estavam inseridos como casos novos em tratamento e/ou em tratamento de reação hansênica, notificados no período compreendido entre os anos de 2018 a 2020, registrados no Sistema de Informação de Agravos de Notificação (SINAN).

Teve como critério de inclusão homens e mulheres classificados como casos novos e/ou em tratamento de reação hansênica, notificados e em atendimento no período de 2018 a 2020 e que tenham idade igual ou maior de 18 anos que aceitaram assinar o Termo de Consentimento Livre e Esclarecido (TCLE). E exclusão daqueles participantes menores de 18 anos e com idade igual ou maior de 18 anos que se sentiram desconfortáveis com a pesquisa e não desejaram responder o formulário semiestruturado, e/ou que não aceitaram assinar o Termo de Consentimento Livre e Esclarecido (TCLE), e/ou não se sentirem seguros em participar deste estudo.

Os participantes da pesquisa receberam, inicialmente, uma ligação telefônica da enfermeira da Unidade, nesse momento foram expostos os objetivos e informações referentes à pesquisa. Após o aceite, entrou-se em contato com os participantes novamente por meio de ligação telefônica, marcando o melhor dia e horário para comunicação via rede social (WhatsApp ${ }^{\circledR}$ ) por chamada de vídeo, oportunidade em que foi lido e disponibilizado o Termo de Consentimento Livre e Esclarecido (TCLE) e explicado a importância da pesquisa.

Para os participantes que tinham consulta médica agendada na Unidade, a entrevista foi realizada de forma presencial na sala da enfermeira, de forma reservada e individualizada, momento em que foi realizada a leitura e assinatura do TCLE.

Cada participante foi identificado por um código para garantir o seu anonimato. Para os participantes contatados via WhatsApp ${ }^{\circledR}$, o preenchimento do formulário de perguntas fechadas foi realizado pela pesquisadora e as entrevistas gravadas (dos participantes via WhatsApp ${ }^{\circledR}$ e presencial) e posteriormente transcritas. Após transcrições das entrevistas, os dados foram analisados segundo a análise de Conteúdo de Bardin (2011) na modalidade Categorial. Dessa maneira, a análise proporcionou uma interpretação mais apurada do conteúdo apresentado pelos participantes da pesquisa, de acordo com as manifestações da hanseníase na região de cabeça e pescoço e os impactos no seu cotidiano.

Considerando a situação da pandemia que os brasileiros estão vivenciando no país. E por conseguinte, a reorganização dos serviços de saúde para atender à síndrome respiratória aguda (COVID-19), algumas pesquisas foram prejudicadas pela inacessibilidade ao serviço de saúde decorrente dessa situação e das restrições impostas pelas autoridades sanitárias.

A pesquisa qualitativa se propõe a obter informações de natureza subjetiva que não podem ser quantificados, buscando aprofundar a compreensão de um grupo social ou organização. É tratado por meio da história, do universo, dos significados individuais, crenças, valores e das atitudes dos atores sociais (Minayo, 2013).

O formulário semiestruturado constitui-se como um instrumento essencial nas pesquisas sociais que visam obter informações diretas, face a face entre os sujeitos da pesquisa e o pesquisador. Trata-se de um procedimento utilizado na investigação social, coleta de dados, para ajudar no diagnóstico ou no tratamento de um problema social (Marconi \& Lakatos, 2010).

Para a análise dos dados qualitativos, foi utilizada a análise de conteúdo de Bardin que consiste em uma metodologia que se aplica a discursos diversos, categorizando e classificando os componentes do significado das mensagens, de forma objetiva e sistemática (Bardin, 2011).

De acordo com Bardin, para a realização da análise do discurso são necessárias três etapas: (1) pré-análise - quando se organiza o material, compondo o corpus da pesquisa; (2) exploração do material quando se faz a leitura flutuante, assim como a escolha das unidades de registro e a categorização do material; (3) tratamento dos resultados por meio de inferências, retornando ao referencial teórico para dar sentido em profundidade às interpretações (Bardin, 2011). 


\section{Resultados e Discussão}

A partir da transcrição das falas dos 41 participantes do estudo foi realizada a análise do conteúdo apresentado nas falas. Foram identificados 6 fatores que se destacaram e dizem respeito ao impacto da hanseníase no cotidiano desses pacientes. A partir dessa percepção, foram geradas 6 categorias temáticas, a saber: Trajetória percorrida até chegar ao diagnóstico de hanseníase; Vivência e sentimentos das pessoas atingidas pela Hanseníase; Mudanças ocorridas no convívio social, familiar e profissional; Impacto das manifestações na região de cabeça e pescoço no cotidiano das pessoas atingidas pela hanseníase; O estigma e o meio social; e, Superação das dificuldades decorrentes das manifestações na região de cabeça e pescoço.

Tais categorias foram discutidas a seguir, sendo apresentadas as falas dos participantes que expressam como estes se sentem com relação a doença, as dificuldades do diagnóstico de hanseníase e como vivenciam o estigma e a exclusão, muitas vezes desenvolvendo transtornos físicos e emocionais. Importante destacar que, para garantir o sigilo dos entrevistados, eles foram identificados pela sigla "HAS" seguida de ordem numérica crescente.

\section{A trajetória percorrida até chegar ao diagnóstico de hanseníase}

A OMS lançou a estratégia mundial de eliminação da hanseníase com o objetivo de assegurar a adesão ao tratamento, promover a detecção precoce de casos e reforçar a conscientização dos pacientes e das comunidades sobre hanseníase (OMS, 2016; Brasil, 2016).

O diagnóstico da hanseníase ainda acontece de forma tardia, aproximadamente em um ano e meio a dois anos após o aparecimento dos sintomas que, por vezes, quando surgem lesões sensitivas e/ou motoras, deformidades e incapacidades físicas. A busca tardia do atendimento nos serviços de saúde, a falta de informação sobre os sinais e sintomas, a dificuldade de acesso ao serviço de saúde de referência e profissionais não capacitados para detectar a hanseníase, são fatores que que influenciam o diagnóstico tardio e impactam na qualidade de vida dessas pessoas (Tavares, 2014).

Os relatos, expostos a seguir, contam as experiências vivenciadas pelos participantes da pesquisa até chegar ao diagnóstico e tratamento, percorrendo um caminho de incertezas e estigmas.

O primeiro diagnóstico foi que eu cai de moto ai ralou o braço, ai sangrou e eu não senti, passei a mão e tinha muito sangue, ai ficou, tomei medicamento sarou, ai ficou, ai uma faixa de 02 a três meses, saiu as manchas ai procurei o médico, ai me encaminhou para um dermatologista, ai fui para o João Paulo II, lá no jacintinho, ai fui, chegou lá ele passou a biopsia do cotovelo, voltei para pegar o resultado e deu negativo, mas ele disse que iria tratar como hanseníase, ai passou o medicamento que é um ano para tomar, ai voltei para Rio Largo, que mora lá, fui ao posto e a enfermeira disse que não irai tratar hanseníase, porque não era, era apenas dermatite, ai olho o diagnóstico do médico e disse que não ia fazer, ai que se alastrou-se mais, ai que saiu manchas, passou 03 meses nisso, vai e volta, ia lá e ela não queria fazer o tratamento, ai voltei para o João Paulo II, me consultei com a enfermeira ai comecei o tratamento, lá em Rio Largo a enfermeira recusou. (HAS 4)

Para mim foi chocante, apesar do meu marido ter tido há 05 anos, só que o dele descobriu logo e não fico como estou hoje, naquele tempo passaram para eu tomar BCG, eu não dei valor, não fui e quando apareceu a mancha, eu procurei tratamento e os médicos diziam que não era, até chega nessa condição que estou hoje, é um negócio meio assim, que nem a todo mundo eu digo viu. (HAS 23) 
[...] tenho revolta, eu procurei o tratamento muito antes de chegar nesse tratamento que estou tomando agora, porque pelo amor de Deus me deixa debilitada, eu fiquei revoltada por procurar atendimento antes, os médicos que eu fui ficaram dizendo que não era, nenhum dermatologista que eu fui, diagnosticou. (HAS23)

O tratamento da hanseníase está disponível nas Unidades Básicas de Saúde pública. A Poliquimioterapia (PQT) é uma associação de Rifanpicina, Dapsona e Clofazimina. Esse tratamento é efetivo para matar o bacilo e evitar a evolução da doença, proporcionando a cura. Com o tratamento adequado, a transmissão da doença é interrompida, rompendo a cadeia epidemiológica. A dose da PQT é ajustada de acordo com classificação operacional e/ou forma clínica, delimitando também o tempo do tratamento e alta por cura (Brasil, 2017).

A PQT trouxe novas possibilidades de eliminação da doença e fez avançar a atenção para a prevenção, evitando as complicações clínicas decorrentes dos processos inflamatórios. Existem estudos buscando a identificação e associação laboratorial entre carga bacilar e formas multi ou paucibacilares, mas quando se procuram prevenções clínicas efetivas, seguras e de baixo custo, buscar associar o conhecimento das formas clínicas da doença, o diagnóstico preciso dos tipos de reação hansênica e sua evolução, é fundamental para definir critérios que decidam ações preventivas clínicas em hanseníase (Souza, 2010).

Devido aos danos neurais associados às reações hansêncas, as pessoas atingidas pela hanseníase podem apresentar deformidades e incapacidade físicas. E estes fenômenos inflamatórios agudos, são provocados pelo sistema imunológico à presença do bacilo de Hansen e se traduzem por alterações corporais que comprometem a aparência e que estão ligadas ao diagnóstico tardio. Tais reações, quando não tratadas, são responsáveis pelos danos neurais que conduzem a incapacidades físicas, podendo ocorrer antes, durante ou após a instituição da poliquimioterapia. Uma proporção considerável de pacientes sofre de reações hansênicas a qualquer momento no processo da doença: antes, durante ou após o tratamento (Santos et al, 2018).

[...] foi triste, fiquei 6 meses para descobrir essa doença, depois disso fui internado no hospital para descobrir que estava com essa doença, os médicos só faziam tratamento errado, fiquei todo inchado, cheio de nódulos no corpo, depois de 15 dias tive alta e fui em um atendimento no II Centro para fazer tratamento, essa doença não é fácil, é uma doença que todos os pacientes ficam com deficiência, tinha caroço no corpo todo, no rosto, nas orelhas, o corpo todo inchado, doía o corpo todo. (HAS 39)

Com frequência, as pessoas atingidas pela hanseníase são vítimas de estigma e discriminação. Isso tem impacto negativo no acesso ao diagnóstico, resultados do tratamento, além de afetar o relacionamento social. O estigma é uma causa importante de atraso do diagnóstico, o que facilita a transmissão da infecção nas famílias e comunidade (Brasil, 2016).

Fiquei triste, porque isso é terrivel, atrapalha a vida da pessoa, quando eu descobri, a minha patroa me colocou para fora, tem gente que tem muito preconceito, que ela que me levou no Hospital, uma amiga dermatologista disse que era hanseníase, mas tinha que fazer exame para confirmar, quando soube mesmo, ela me colocou para fora, eu trabalhava lá 4 anos. (HAS 18)

\section{Vivência e sentimentos das pessoas atingidas pela hanseníase}

No que diz respeito ao processo saúde-doença, homens e mulheres vivenciam, de modos diferentes, a hanseníase. Nos dias atuais, o corpo tem sido valorizado nos aspectos relacionados à estética, à sexualidade e às relações sociais de gêneros. $\mathrm{O}$ 
diagnóstico de hanseníase gera uma instabilidade psicológica, orgânica, impacta diretamente na autoestima, na plenitude da relação sexual, na relação com familiares e, por efeito, gera o medo de não aceitação no meio social (Dias et al, 2017).

A maneira em que a pessoa se comporta perante as mudanças vivenciadas pela hanseníase no tratamento, embora tenha cura, há um receio constante em relação às sequelas irreparáveis que afetam a funcionalidade dos órgãos importantes para locomoção ou que afetam a imagem, tais como, feridas na face, mancha, caroços. As medicações alteram a pigmentação da pele. Essas transformações impactam na autoimagem (Costa \& Brandão, 2016).

[...] foi difícil, foi bem devastador, primeiro pela falta de informação, segundo pelo preconceito, meu próprio preconceito, eu não queria que ninguém soubesse, nem a minha família, na primeira vez e agora na segunda vez foi devastador, eu não acreditava que iria passar tudo de novo, porque eu já tinha feito o tratamento todo certinho, tinha recebido alta, e na minha cabeça nem existia aquele período na minha vida, ai tive que reviver tudo novamente. Só que agora com mais informações, mesmo sabendo de tudo, foi bem difícil. (HAS 16)

[...] não, quando saia na rua o povo não sabia o que era, mas quando eu me olhava no espelho eu achava horrível, negócio feio, ai eu disse vou comprar um pó para passar no rosto para esconder, mas que é feio é, e ainda tava pior, depois que comecei a tomar o remédio melhorou um pouco, muito ruim, Deus me livre, ainda bem que meus filhos não tem. (HAS 18)

A hanseníase traz marcas socioculturais dolorosas até os dias atuais. Percebe-se que o medo, a falta de informação, o preconceito e a discriminação encontram-se enraizados no processo de construção social da hanseníase e, infelizmente, ainda são fatores predominantes que dificultam ao extremo o enfrentamento da doença (Leão e Silva et al, 2020).

Fiquei surpreso, depois não quis aceitar por conta que os exames tinham dado negativo, depois normal e fui tratar, porque todo mundo pode ser acometido e fui fazer o tratamento. (HAS 3)

[...] para mim foi uma surpresa, descobrir que ia fazer um tratamento que era demora, eu ná fiquei muito legal não, aí tive que passar por psiquiatra e psicólogo para poder entender mais. (HAS 5)

Por muitas vezes ocorrem mudanças físicas com o desenvolvimento da doença, o que contribui para a formação de estigmas sociais. É visível a forma pela qual a hanseníase, além de afetar fisicamente as pessoas, também pode provocar repercussões na autoestima, levando as pessoas afetadas ao auto preconceito por medo de conviver em sociedade de encarar a sociedade, tendo de esconder as manchas da doença por vergonha (Argentino, Costa \& Silva 2019). Em sendo assim, as pessoas afetadas tornam-se pessoas retraídas, tímidas e, por vezes, desmotivadas.

[...] é preocupante, foi triste, eu não falei para as pessoas, só os meus parentes porque tive que trazer, mas eu encaro a doença seja ela qual for, encaro com naturalidade, é preocupante ter de passar para outra pessoa, para mim é triste isso, mas fiquei tranquilo, só deixei de fazer umas coisas que fazia antes. (HAS 17)

[...] terrível, não gosto, não queria ter essa praga, mas fazer o que né, é uma coisa que a gente não pode nem contar para ninguém, o povo tem muito preconceito, tem que conviver só para você e família, quando fala para o povo, já se afastam, é muito ruim. (HAS 18) 
[...] eu achei que iria ser moleza, não era nada de mais, mas agora estou vendo que é bem difícil, pelos sintomas que sinto desde quando comecei o tratamento, é uma sensação que você vai morrer, devido o que sente. (HAS 27)

Viver com a hanseníase exige empoderamento do paciente e foco na redução de estigma. É necessário que haja incentivo a programas de reabilitação, participação em grupos de apoio e integração social, para minimizar as dificuldades vivenciadas no dia a dia (D’Azevedo et al, 2019).

[...] alterou, a minha vida porque as vezes queria fazer outras coisas e não conseguia fazer, as vezes me desmotivava, não vou mentir. (HAS 1)

Foi muito difícil, porque eu era uma pessoa sadia e de repente, foi como uma bomba, através disso acabou a minha vida, perdi de trabalha, deixei de fazer as coisas que eu gosto, nem pescar eu posso mais, quer dizer, perdeu tudo para mim, vou dizer um negócio a senhora, a pessoa sem saúde a pessoa não é nada, eu não esperava isso, ninguém pede para adoecer. (HAS 28)

\section{Mudanças ocorridas no convívio social, familiar e profissional}

É perceptível, nas narrativas, que as pessoas atingidas pela hanseníase passam a conviver com o medo no seu cotidiano, bem como com angústia, pesar, receio, ao ponto de fazê-las mudar sua rotina, com medo de sofrer discriminação por amigos e por familiares. Nas atividades laborais, o afastamento dos amigos torna o processo de adoecimento mais doloroso. Aliás, as narrativas expostas apresentam o mesmo problema em outras áreas da vida para a pessoa afetada.

[...] no começo, quando eu trabalhava, e descobri a doença em 2005, um amigo da sala ficava jogando, dizendo uma coisa comigo, e eu ia para o banheiro chorar, dizendo que ia pegar, por ser um ambiente fechado, na época eu era estagiária de recursos humanos. (HAS 1)

[...] os grupos de colegas do trabalho que ficaram preocupados comigo, se eu estava bem, que por exemplo quando eu sair do hospital, fui fazer perícia em Sergipe, ai meu amigo lembrou que tínhamos nos inscrito em um concurso do IFAL, ai viajei para Bahia, 10 dias após sair do hospital, meu amigo ficava preocupado comigo, porque meus pés inchavam, tinha dificuldade para andar, os amigos ajudaram no processo. (HAS 2)

[...] sim, alterou muito, perdi a força do braço esquerdo, a sensibilidade dos dedos, e como eu trabalhava como cozinheiro, agora trabalho como servente com o meu tio, tem que está olhando os dedos, porque machuca e a gente não sente e com esse negócio de pandemia, deu ruim para ganhar o sustento. (HAS 5)

A falta de informação impacta na vida social, pelo fato de precisar esconder a doença das pessoas com quem convive no dia a dia. O acolhimento dos familiares no serviço de saúde para conversas francas e esclarecedoras sobre a doença, irá servir para mostrar que a hanseníase tem tratamento e cura e, em sendo assim, terá como propósito levar informações para que a pessoa afetada pela hanseníase vivencie esse processo de uma maneira mais leve junto a seus familiares e amigos

A hanseníase causa grande impacto em todas as áreas da vida do seu portador, seja no ambiente de trabalho, nas relações sociais e até mesmo no âmbito familiar. Problema ocasionado pelo impacto histórico da doença, que permanece na mentalidade da sociedade como doença mutilante e incurável, tendo como consequência rejeição, discriminação e exclusão social do doente. Além do sofrimento causado pelo estigma da doença, as deformidades e incapacidades físicas também trazem 
grande impacto psicossocial. Limitações que impactam na qualidade de vida das pessoas atingidas por essa doença (Santos \& Ignotti, 2020).

[...] não, logo quando comecei o tratamento a pele da gente fica meio escura, ai eles perguntavam o que vc está fazendo que o seu rosto da escuro, os caras falavam você está igual ao Michel Jackson, os caras lá, mudando de cor, ai eu também não dizia que estava fazendo tratamento de Hanseníase. Porque se disser sempre tem a discriminação. (HAS 4)

[...] os amigos depois que sabe que você tem essa doença eles se afastam, se afasta muito, quem tem sabe que é complicada essa doença. (HAS 9)

As pessoas com hanseníase sofrem mais restrições profissionais, principalmente aquelas que possuem baixa qualificação, possuindo mais chances de ficarem sem emprego, o que as leva, portanto, a esconderem a existência da doença no intuito de evitarem problemas financeiros que podem inclusive dificultar a realização do tratamento da doença (Silva et al., 2020).

[...] na firma que eu trabalhei, quando soube que eu estava com essa doença me mandou ir embora, tive que ir no médico para conseguir voltar a trabalhar. (HAS 11)

Até hoje estou no trabalho e nunca falei para eles, para não ser rejeitado, né?! (HAS 14)

\section{[...] fui demitida a patroa tinha medo de pegar nos filhos dela. (HAS 18)}

Nas entrevistas, percebe-se que as pessoas atingidas pela hanseníase precisam mudar a forma de pensar e de agir, para que haja a possibilidade de aceitação no meio social. Por isso, torna-se imprescindível que sejam orientadas acerca da doença e de seu tratamento, a fim de ser possível as mudanças necessárias no dia a dia, pois esconder-se em nada vai propiciar o enfretamento da doença. Como de fato convivem com a tristeza pela falta de informação das pessoas que coabitam, o acolhimento por parte dos serviços de saúde se faz necessário como estratégia de promoção do autocuidado. Ações e atividades que o próprio paciente realize, entendendo os riscos e promovendo por meio de medidas a promoção, a prevenção e a recuperação da sua saúde, tornando possível o emponderamento pessoal, e sus inserção em grupos de apoio ao autocuidado (D’Azevedo et al, 2019).

\section{Impacto das manifestações na região de cabeça e pescoço no cotidiano das pessoas atingidas pela hanseníase}

O impacto causado pela hanseníase pode interferir negativamente no cotidiano das pessoas, devido às situações de preconceito, exclusão, discriminação e abandono, dessa forma, os problemas psicossociais são potencializados. Os acometimentos dos nervos, as incapacidades físicas e deformidades são de grande impacto no cotidiano, sendo responsáveis pela exclusão dos trabalhadores do mercado de trabalho, do convívio social e da sua participação na comunidade (Leão e Silva et al, 2020; Brasil, 2017), como podemos ver abaixo:

[...] apareceu uma mancha no rosto, eu pensava que era um sinal vermelho, quando ia para o sol ficava aquele vermelhão, muita gente se afastava, e no trabalho muita gente teve medo, meu patrão não aceita que eu volte para o trabalho. (HAS 24)

[...] tive nódulos e manchas, no rosto, a visão também foi atingida, enxergava e não enxergo mais, atingiu meus osso, atingiu a minha força, não tenho mais força para nada, através disso, essa doença é maldita, acabou com tudo 
isso, não levanto um saco de cimento, não tenho força nas pernas também, não aguento subir uma escada, para andar também fico cansado, fraco, fico parando nos cantos, dói os meus ossos todos, não tenho força nem nas pernas, nem no braço, acabou mesmo, só quem sabe é quem passa. (HAS 28)

[...] tive manchas e caroços no rosto, alterou muito a minha vida, é um negócio que a pessoa não fica bom, está dentro dos ossos, nos nervos, sinto um monte de agulha furando, eu dou até tapa quando sinto furando. (HAS 36)

A avaliação das incapacidades é de extrema relevância para a educação e promoção do autocuidado. A prevenção é feita por meio de procedimentos e exercícios, que o próprio indivíduo, devidamente orientado, incentivado e capacitado, deverá realizar regularmente no próprio domicílio, durante o tratamento e após a alta. Para tanto, é preciso haver uma mudança de comportamentos, com uma relação de confiança entre o paciente e a equipe de saúde, além da incorporação do autocuidado na rotina dos indivíduos (D’Azevedo, Freitas \& Nascimento, 2018).

Percebe-se que os entrevistados apresentam manifestações na região de cabeça e pescoço ou algum tipo de incapacidade física, o que reflete no diagnóstico tardio da doença, e impacta diretamente no cotidiano, trazendo revolta, vivenciando o estigma, tristeza, medo, angústia, vergonha, rejeição, exclusão e por vezes a depressão.

[...] tive manchas no rosto, não saio mais na rua, tenho vergonha de fazer até feira, porque estou toda manchada, as pernas tudo mеи тиdou, mudou minha rotina, eu fico com vergonha, porque as pessoas ficam perguntando, fica perguntando se essa mancha são queimaduras, e eu fico sem saber o que falar, ai prefiro não sair de casa, peço para alguém fazer a minha feira, minha rotina mudou totalmente, eu gostava de fazer as minhas coisas, minhas compras, cuidar dos meu filhos, da minha neta, e não faço mais nada hoje, e isso mudou demais a minha vida. (HAS 38)

[...] nódulos na orelha, mancha no pescoço, eu estou triste, devido as coisas que sinto, não poder exercer a minha profissão nas coisas que trabalho, quando a Dra falou que eu ria usar protetor solar, casaco, devido a pele, ai falei tudo bem, vou continuar trabalhando, só que devido as coisas que estou sentindo já bateu angustia, tristeza, então para mim já não foi legal, tenho família, esposa, filha, vejo eles precisando e não posso ajudar. (HAS 27)

\section{O estigma e o meio social}

As metas da Estratégia Global para 2020 são alcançar: a redução da taxa de grau 2 de incapacidade física para menos de um caso por 1.000.000 de habitantes até 2020; o índice zero para crianças diagnosticadas com grau de incapacidade grau 2; zero países com leis discriminatórias contra pessoas acometidas pela doença (BRASIL, 2019).

A hanseníase mantém-se como importante endemia para a saúde pública do Brasil, sobretudo por sua magnitude e pelo poder incapacitante, fatores que contribuem para a ocorrência desse estigma e de atitudes discriminatórias e exclusão social associados à doença (Brasil, 2019), como podemos observar nas falas abaixo, onde são relatados tais fatos.

[...] o povo me chamava de jacaré, e ficavam mangando, mais depois se acostumaram, no meio do povo, é complicado, não é fácil não, quando chega perto de alguém um diz uma coisa, é muita coisa que você ouve no dia a dia. (HAS 9)

No começo fui descriminado 03 vezes, no INSS por duas mulheres, por minha prima e meu cunhado. (HAS 7)

[...] porque nem todo mundo quer ficar perto de você, então não é coisa boa não. (HAS 10) 
Desse modo, considerando as peculiaridades clínicas, epidemiológicas e psicossociais da hanseníase, as ações para o controle da doença no país baseiam-se, por exemplo, na busca ativa para detecção precoce dos casos, tratamento oportuno, prevenção e tratamento das incapacidades; reabilitação; manejo das reações hansênicas e dos eventos pós-alta; investigação dos contatos de forma a interromper a cadeia de transmissão, além da formação de grupos de autocuidado e ações adicionais que promovam o enfrentamento do estigma e discriminação às pessoas acometidas pela doença (Brasil, 2019).

O conhecimento da condição de portador de hanseníase desencadeia nos indivíduos preocupações e mudanças significativas em sua vida pessoal, principalmente relacionadas à família. Quando não tratada, as sequelas podem ser desfigurantes, mutilantes e incapacitantes. Estas incapacidades constituem, na realidade, a grande causa do estigma e isolamento das pessoas atingidas pela hanseníase na sociedade, fazendo com que se instale o isolamento social e familiar (Oliveira et al, 2016).

[...] senti, quando peguei essa doença as pessoas se afastaram, até eu fiquei com medo, que a minha família se aproximasse de mim, não chegava mais perto dos meus netos. (HAS 39)

\section{[...] na minha casa era tudo separado, copos, pratos, gafo e faca. (HAS 36)}

O estigma é um atributo que desvaloriza a pessoa, gerando desigualdade social, reduzindo as oportunidades, impondo a perda da sua própria identidade, a pessoa passa a enxergar-se diferente do modelo que a sociedade impõe, com uma imagem deteriorada é preciso tratar a hanseníase e os doentes acometidos por essa patologia como qualquer outra doença. Acabando com o mito que o indivíduo doente recebeu castigo divino, visando reparar décadas de isolamento social (Dantas et al, 2020).

Podemos observar nas falas aqui reproduzidas que são expressas as sensações vivenciadas pelo estigma no cotidiano, insegurança em conviver no meio social, as pessoas afetadas pela hanseníase escolhem não falar para seus familiares, amigos e colegas de trabalho sobre sua doença, por medo de ser discriminado e passa a conviver com o peso do estigma mesmo sabendo que se trata de uma doença que tem cura.

Só tive manifestações no corpo, quando alguém perguntava eu dizia que era pano branco, não falava, porque para mim era constrangedor, feio, mas tranquilo. (HAS 17)

As pessoas quando sabem se afastam um pouco, achando que vão pegar, mas fazendo o tratamento certinho não passa para as outras pessoas. (HAS 22)

Teve muita gente que se afastou de mim, me chamaram de corpo de pereba, tem pouco tempo que estou começando a sair. (HAS 25)

[...] lesado, as pessoas têm nojo da pessoa, não querem nem chegar perto da pessoa, quando eu era bom as pessoas chegavam perto de mim, brincava, me abraçava, hoje as pessoas estão afastadas, principalmente onde eu trabalhava, que trabalha em condomínio, hoje quando eu passo as pessoas falam de longe, achando que vai pegar, não vai pegar mais, mas quem está com os sintomas sou eu, com manchas no rosto. (HAS 28)

O estigma traz consequências negativas ao tornar as interações sociais desconfortáveis, ao limitar redes sociais, comprometer a qualidade de vida e gerar desemprego, perpetuando o ciclo da exclusão social e econômica. Dessa forma, o estigma aumenta a vulnerabilidade de pessoas e grupos, gerando prejuízos diretos à saúde e à representação social daqueles que atinge (Levantezi, Shimizu \& Garrafa, 2020). 
Mesmo a hanseníase tendo tratamento e cura, a redução do aparecimento das incapacidades físicas, devido à inserção de tratamento precoce, ainda é uma doença que provoca estigmas e exclusão, pelo fato de ser constituir uma doença milenar, cercada de histórias e preconceitos na antiguidade.

Os profissionais, que atuam na atenção básica de saúde, têm a qualificação técnica para aplicar medidas socioeducativas em ambiente escolar e em comunidades, como também podem ministrar educação em saúde em sala de espera. Em razão disso, caso tais ações sejam colocadas em prática, o preconceito poderá ser minimizado. Facilmente, esses profissionais poderão promover concretamente esse trabalho de alcance pela inclusão social e transmitir o conhecimento sobre a doença para a comunidade. As ações referem-se às orientações acerca da transmissão e do tratamento da doença, e ressaltam a cura.

Em sendo assim, se forem postas à execução, poderá ser promovido melhor entendimento a respeito da doença e, dessa maneira, as estratégias aplicadas, em ambiente escolar, nas comunidades e em sala de espera, vão minimizar a discriminação, a intolerância, o repúdio e a rejeição impostas pela doença e, assim, possibilitar a reintegração à sociedade das pessoas atingidas pela hanseníase.

\section{Superação das dificuldades decorrentes das manifestações na região de cabeça e pescoço das pessoas atingidas pela hanseníase}

A origem da palavra "superação" vem do latim superatio.onis. O significado de superação está voltado para a ação de superar, de ultrapassar uma situação desagradável, perigosa, ação de vencer, de conseguir a vitória; sobrepujamento (Ferreira, 2010).

A hanseníase tem um potencial incapacitante bastante significativo. Pode resultar em diversos transtornos para o desempenho das atividades de vida diária da pessoa acometida. Transtornos podem ser evitados por meio de diagnóstico e tratamento precoces. Nesse sentido, há uma estratégia em curso no Brasil, para a implantação de grupos de apoio ao autocuidado nos serviços de saúde, dando suporte a pessoas atingidas pela doença. A proposta central dos grupos de apoio ao autocuidado é reunir pessoas com os mesmos agravos e interesses, que desejam aprender a conviver com suas dificuldades, por meio da troca de experiências (D’Azevedo, Freitas \& Nascimento, 2018).

Há, nas narrativas das pessoas acometidas pela hanseníase, a latente necessidade de colocar em prática um novo pensamento para conquistar comportamentos de vitória.

Vou levando como Deus quer, só não posso para de tomar o remédio que eu quero ficar boa, não vejo a hora de ter alta e parar de tomar o remédio. (HAS 6)

O preconceito eu tiro de letra, mas a sequela que é o problema eu quero dar um nó no cadarço e ele não vai, aí eu xingo eu mesmo, se pegar um copo com a direita eu sinto dificuldade aí já faço com a esquerda, essas coisas assim, o que me atrapalha mesmo é só o pé e a mão desse jeito. (HAS 13)

[...] foi difícil até no modo de vestir, eu só usava saia longa e calça comprida, porque apareceu mancha nas pernas, eu só usava essas roupas para não está explicando para ninguém o que era, eu achava horrível. (HAS 16)

[...] tipo força de vontade, porque eu tinha uma rotina e tive que me adaptar a outra totalmente diferente. (HAS 22)

[...] ainda não superei não, ainda não visto as roupas que gosto de vestir, não visto roupa sem manga, não visto short e essas roupas eu gostava de vestir, e quando eu chego em casa perto dos vizinhos que pergunta que manchas são essas, eu digo é coisa de pele, estou fazendo tratamento, mas quando saio de casa só saio de calça. (HAS 23) 
Nos grupos de apoio de autocuidado, devem residir ações educativas voltadas para a melhora da qualidade de vida dos participantes, para transmitir informações de qualidade sobre a doença e ensinar uma nova maneira de entender e de pensar a doença em contextos diferentes.

Levadas a efeito, estarão as pessoas acometidas motivadas a ultrapassar as dificuldades impostas pela doença, aprendendo a lidar com os obstáculos com foco em resultados expressivos do que não imaginava ser capaz numa verdadeira troca de conhecimentos entre as pessoas acometidas e os profissionais mutuamente.

O desejo de cada uma delas é não se permitir permanecer abalada pelas dificuldades, mas vencer os limites que a doença impõe. A vontade de vencer medos e fraquezas com apoio de amigos e da família e, também, através da fé, são as expectativas de cada uma das pessoas entrevistadas. Confiança em Deus, torna-se impulso para acreditar na cura. Por isso tudo, o grupo de autocuidado serve como ferramenta de acolhimento, vínculo, interação e troca de experiências.

\section{Considerações Finais}

As manifestações clínicas da hanseníase causam impacto direto na sua qualidade de vida, convívio em sociedade e dificuldade na aceitação relacionada a autoimagem. As dificuldades encontradas pelos participantes iniciaram desde antes da descoberta do diagnóstico. O preconceito com relação as mudanças físicas foram descritas por estes entrevistados, com a mudança da sua rotina e atividades diárias em detrimento da patologia. Apesar da hanseníase ser uma doença endêmica no estado de Alagoas, a falta de capacitação e/ou educação permanente dos profissionais da atenção primária fragilizam o diagnóstico precoce, como também, a ausência de uma equipe multidisciplinar para suprir também as demandas voltadas a saúde mental dos pacientes acometidos.

Por fim, a hanseníase causa um impacto significativo na vida e cotidiano das pessoas atingidas, principalmente para aqueles que apresentam manifestações clínicas visíveis em regiões que não conseguem ficar cobertas, como a cabeça e o pescoço. O diagnóstico precoce, tratamento adequado e acompanhamento multidisciplinar contínuo e qualificado são de suma importância.

O estudo ainda indica ser necessário o aprofundamento da temática, com pesquisas que considerem a perspectiva de outros contextos que envolvem a doença, tais como os familiares, os serviços e os profissionais de saúde, buscando o conhecimento e possíveis contribuições direcionadas para o foco em busca ativa, tratamento precoce, incentivo a grupos de autocuidado, acolhimento e garantia de atendimento de qualidade.

\section{Referências}

Argentino, S., Costa. N. L., \& Silva. W. C. S. S. (2019). Os Estigmas Sociais Vivenciados por Pacientes de Hanseníase em Marabá - Pará. X Semana Acadêmica. Amazônia: desafios, avanços e contribuições na Educação, Saúde e Meio ambiente. https://paginas.uepa.br/campusmaraba/wpcontent/uploads/2019/10/OS-ESTIGMAS-SOCIAIS-VIVENCIADOS-POR-PACIENTES-DE-HANSEN\%C3\%8DASE-EM-MARAB\%C3\%81-

$\%$ E2\%80\%93-PAR\%C3\%81.pdf

Bardin, L. (2011). Análise de conteúdo. (4a ed.), Edições.

Brasil. Ministério da Saúde (2019). Ministério da Saúde. Secretaria de Vigilância em Saúde. Departamento de Doenças de Condições Crônicas e Infecções Sexualmente Transmissíveis. Estratégia Nacional para Enfrentamento da Hanseníase 2019-2022/Ministério da Saúde, Secretaria de Vigilância em Saúde, Departamento de Doenças de Condições Crônicas e Infecções Sexualmente Transmissíveis - Brasília: Ministério da Saúde

Brasil. Ministério da Saúde (2017). Secretaria de Vigilância em Saúde. Departamento de Vigilância das Doenças Transmissíveis. Guia prático sobre a hanseníase [recurso eletrônico] / Ministério da Saúde, Secretaria de Vigilância em Saúde, Departamento de Vigilância das Doenças Transmissíveis.:Ministério da Saúde. https://portalarquivos2.saude.gov.br/images/pdf/2017/novembro/22/Guia-Pratico-de-Hanseniase-WEB.pdf

Brasil. Ministério da Saúde. (2017). Secretaria de Vigilância em Saúde. Coordenação-Geral de Desenvolvimento da Epidemiologia em Serviços. Guia de Vigilância em Saúde: volume 2 / Ministério da Saúde, Secretaria de Vigilância em Saúde, Coordenação-Geral de Desenvolvimento da Epidemiologia em Serviços. Ministério da Saúde. https://bvsms.saude.gov.br/bvs/publicacoes/guia_vigilancia_saude_volume_2.pdf

Brasil. Ministério da Saúde. (2020). Secretaria de Vigilância em Saúde. Boletim Epidemiológico Especial. Hanseníase. https://antigo.saude.gov.br/images/pdf/2020/May/22/boletim-hanseniase-2020-web.pdf 
Brasil. Ministério da Saúde. (2016). Secretaria de Vigilância em Saúde. Departamento de Vigilância das Doenças Transmissíveis. Diretrizes para vigilância, atenção e eliminação da Hanseníase como problema de saúde pública: manual técnico-operacional [recurso eletrônico] / Ministério da Saúde, Secretaria de Vigilância em Saúde, Departamento de Vigilância das Doenças Transmissíveis. Ministério da Saúde. https://portalarquivos2.saude.gov.br/images/pdf/2016/fevereiro/04/diretrizes-eliminacao-hanseniase-4fev16-web.pdf

Costa, V. D, Brandão, A. A. R (2016). Mulheres vivendo com hanseníase: as representações sociais da doença e o impacto na identidade. Simpósio Linguagens e Identidades da/na Amazônia Sul-Ocidental. Anais do Simpósio Linguagens e Identidades da/na Amazônia Sul-Ocidental, Rio Branco.1: 1-15.

D’Azevedo S. S. P., Freitas, E. N., Nascimento, L.O., Santos, D. C. M. \& Nascimento, R. D. (2018). Percepção de pacientes com hanseníase acerca dos grupos de autocuidado. Rev enferm UFPE on line. 12(6), 1633-1639. https://doi.org/10.5205/1981-8963-v12i6a230855p1633-1639-2018

D’Azevedo, S. S. P., Santos, D. C. M., Alves, M. G. T., Souza, N. M. N., Arruda, G. A. \& Lima, M. C. V. (2019). Qualidade de vida de pessoas afetadas pela hanseníase inseridas em grupos de apoio ao autocuidado. Cogitare enferm. 24: e64266. http://dx.doi.org/10.5380/ce.v24i0.64266 '

Dantas, M. M., Reis, Y. da S., Portugal, J. K. A., Reis, M.. H. da S., Dantas, J. de S., Junior, J. C. F. P., Souza, T. T. G., Germano, S. N. F., Cavalcante, A. P. A., \& Silva, L. R. S. (2020). A trajetória de uma vida marcada pelo preconceito e exclusão social em decorrência do estigma da hanseníase: relato de experiência. Revista Eletrônica Acervo Saúde, (43), e3208. https://doi.org/10.25248/reas.e3208.2020

Dias, A. C. N. S., Almeida, R. A. A. S., Coutinho. N. P. S., Correa, R. G. C. F., Aquino, D. M. C. \& Nascimento, M. D. S. B. (2017). Vivência e Sentimentos de Mulheres Portadoras de Hanseníase. Rev Enferm UFPE on line. Recife, 11(supl. 9):3551-7. 10.5205/reuol.10620-94529-1-SM.1109sup201707

Ferreira, A.B.H. (2010). Dicionário Aurélio. 5, Curitiba: Melhoramentos.

Leão e Silva, L. O., Rodrigues, S. M. B., Brandão, M. B. F., Dias, C. A. \& Fernandes, E. T. P. (2020). Representações Sociais do Processo de Diagnóstico e Cura da Hanseníase. Revista Psicologia e Saúde, 12(2), 73-87. https://dx.doi.org/10.20435/pssa.v0i0.859

Levantezi, M., Shimizu, H. E. \& Garrafa, V. (2020). Princípio da não discriminação e não estigmatização: reflexões sobre hanseníase. Rev. Bioét. 28(1). $10.1590 / 1983-80422020281362$

Marconi, M., Lakatos, E. M. (2020). Técnicas de pesquisa. Atlas.

Minayo, M. C. S. (2013). O Desafio do Conhecimento: Pesquisa Qualitativa em Saúde. HUCITEC, p. 406.

Oliveira, S. V. S., Moura, A. D. A., Rodrigues, A. S., Rouberte, E. S. C., Lima, G. G. \& Rodrigues, C. N. A. (2016). Estigma Social em indivíduos com sequelas da hanseníase. Rev. Tendên. da Enferm. Profis., 8(3): 1936-1942.

OMS. Organização Mundial da Saúde (2016). Enhanced global strategy for further reducing the disease burden due to leprosy (2011-2015). Genebra. https://apps.who.int/iris/bitstream/handle/10665/205004/B4304.pdf?sequence=1\&isAllowed=y

Santos, A. R. \& Ignotti, E. (2020). Prevenção de incapacidade física por hanseníase no Brasil: análise histórica. Ciênc. saúde coletiva. 25(10), 3731-3744. $10.1590 / 1413-812320202510.30262018$

Santos, A. L. S., Pereira, I. V., Ferreira, A. M. R. \& Palmeira, I. P. (2018). Percepções de portadores de hanseníase sobre as reações hansênicas e o cuidado de si. Revista Pan-Amazônica de Saúde, 9(4), 37-46. https://dx.doi.org/10.5123/s2176-62232018000400004

Silva, W. C. S., Argentino, N. L. C. S., Oliveira, N. P. \& Rodrigues, D. S. (2020). A estigmatização da Hanseníase: Vivências dos pacientes tratados em uma unidade básica de saúde. Braz. J. of Develop. 6(3), 15824-15833. 10.34117/bjdv6n3-453

Souza, L. W. F. (2010). Reações hansênicas em pacientes em alta por cura pela poliquimioterapia. Revista da Sociedade Brasileira de Medicina Tropical, 43(6):737-739.

Tavares, C. M. (2014). A saúde reprodutiva de mulheres portadores e exportadoras de hanseníase em uma capital do Nordeste- Brasil. (Tese de Doutorado) Universidade de São Paulo. https://teses.usp.br/teses/disponiveis/83/83131/tde-22052014-182652/pt-br.php 